PACS 88.40.jp

\title{
Lateral multijunction photovoltaic cells
}

\author{
A.V. Sachenko, M.R. Kulish, I.O. Sokolovskyi, V.P. Kostylyov \\ V. Lashkaryov Institute of Semiconductor Physics, NAS of Ukraine \\ 41, prospect Nauky, 03028 Kyiv, Ukraine \\ E-mail:n_kulish@yahoo.com
}

\begin{abstract}
In this work, features of solar cells of lateral type were analyzed. The authors offered a design of a monolithic compact solar module with cells electrically connected in series and with a dispersion element (holographic grating). Simulation of a multistage converter was carried out. It has been shown that with increasing the number of cells $n$ the maximum limited efficiency $\eta$ increases. Its maximum values up to $\eta \approx 53.6 \%$ are reached for $n=15$ (in the case of perfectly matched semiconductors and conditions AM0). With further increase of $n$, the efficiency decreases. For a set of concrete semiconductors $\eta \approx 45 \%$ the maximum efficiency for AM0 conditions may be achieved, when the number of cells equals 4 . It has been shown that the calculation results agree with experimental data. The possibility of technical implementation of solar cells with using inkjet printers was investigated, too. Briefly discussed have been the properties of these printers, as well as metal, semiconductor and dielectric inks.
\end{abstract}

Keywords: solar cell, efficiency, dispersive element, inkjet printer, ink.

Manuscript received 24.10.12; revised version received 29.11.12; accepted for publication 26.01.13; published online 28.02.13.

\section{Introduction}

Currently, there is an intensive search for ways to improve the efficiency $\eta$ of converting solar energy into electricity to achieve the limit efficiency $\eta_{m}$ and technical realization of solar cells with efficiency close to $\eta_{m}$. Various approximations were used to estimate $\eta_{m}$ [1-3]. In the Carnot approach, the entropy, dissipation of entropy and entropy generation free from work are taken into account, and the efficiency reaches the value $\eta_{m}=$ $95 \%$. At the same time, losses caused by reradiation are not taken into account. This process is accounted in the Landsberg approach, and the values $\eta_{m}=93.3 \%$ are obtained. These estimates are made being based on the first and second laws of thermodynamics and substantially inflated. To find a more realistic assessment of $\eta_{m}$, Shockley and Quaisser used the model detailed balance between absorption and emission [4]. This model takes into account the following features. 1) Semiconductor absorbs light quanta with the energy $h v$, exceeding the band gap $E_{g} .2$ ) The excess energy of hot electrons is consumed for heating the semiconductor.
3) Generated charge carriers can recombine before field of the $p-n$ junction separates them. 4) Some carriers are lost during their separation in this field. Under these limitations for silicon solar cells $\eta=30 \%$ was get [4]. Calculations that made by Henry gave $\eta=31 \%$ for structures with an optimum band gap [5]. The maximum efficiency of manufactured silicon cells and modules is respectively equal to 25 and $22.9 \%$ [6].

Something closer to the maximum value of the thermodynamic efficiency $\eta_{m}=93.3 \%$ can be achieved by concentration of light onto the entrance surface of the solar cell and formation of semiconductor structures with multiple $p-n$ junctions. We must remember that the concentration of light leads to an increase in the temperature of a $p-n$ junction, which is accompanied by decreasing the efficiency of solar cells [7,8]. So, when the temperature of $\mathrm{Si}$ and GaAs cells is increased by $1{ }^{\circ} \mathrm{C}$, their power decreases approximately by 0.45 and $0.21 \%$ [9]. Increasing the efficiency of solar modules can be realized using the cascade structures with multiple $p-n$ junctions (Fig. 1) $[10,11]$. Thus, when using the detailed balance model to calculate the 
efficiency of each $p-n$ junction structure with multiple $p-n$ junctions, the efficiency value can be achieved as $\eta_{m}=63 \% \quad$ (Fig. 1) for the structure with $9 p-n$ junctions. For a structure with an infinite number of $p-n$ junctions $\eta_{m}=68.2 \%[3]$.

The structure with multiple $p-n$ junctions can be realized either staked multijunction solar cells with each junction by using the corresponding part of the solar spectrum (vertical structure), or the arrangement of several cells laterally (lateral structure). In vertical structures, several semiconductors with different band gaps are deposited layer-by-layer. In each semiconductor, the perspective $p-n$ junction is formed. Used at the bottom is semiconductor with the smallest forbidden gap, and at the top - with the largest one. Each semiconductor layer absorbs only a part of the sunlight spectrum, generating a certain amount of electricity. $p-n$ junctions are connected either by electrical conductors (mechanical structure) or by tunnel junctions (monolithic structure). In the best experimentally realized structures with three junctions, the achieved value is $\eta=42.3 \%$ at 406 suns of the light intensity [6].

However, the vertical structure with a large number of $p-n$ junctions is very difficult for manufacturing because of the need for careful matching the lattice parameters of semiconductors. The number of semiconductors with closed lattice parameters is limited. In addition, technology of manufacturing these structures is difficult and requires to use high vacuum and high temperatures. In mechanically stacked structures, there are significant difficulties with connecting many $p-n$ junctions electrically.

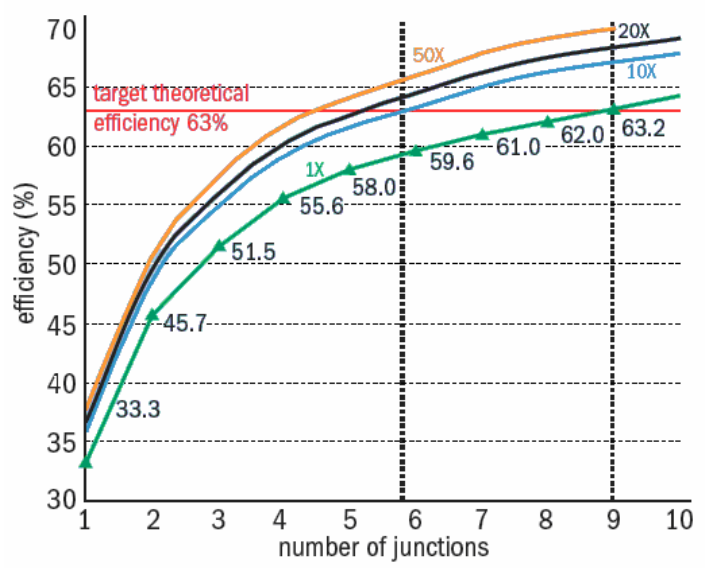

Fig. 1. Theoretical efficiency as a function of the number of $p-n$ junctions under AM1.5G conditions. Calculations are carried out for four intensity sunlight conditions $(1 \times=\mathrm{AM} 1$, $5 \mathrm{G} ; 10 \times=10 \mathrm{AM} 1.5 \mathrm{G} ; 20 \times=20 \mathrm{AM} 1.5 \mathrm{G} ; 50 \times=50 \mathrm{AM} 1.5 \mathrm{G}$, $\mathrm{G}$ indicates that the intensity of light corresponds to the ground level). The numbers near the lower curve correspond to the values of efficiency for the given number of $p-n$ junctions (taken from [11]).

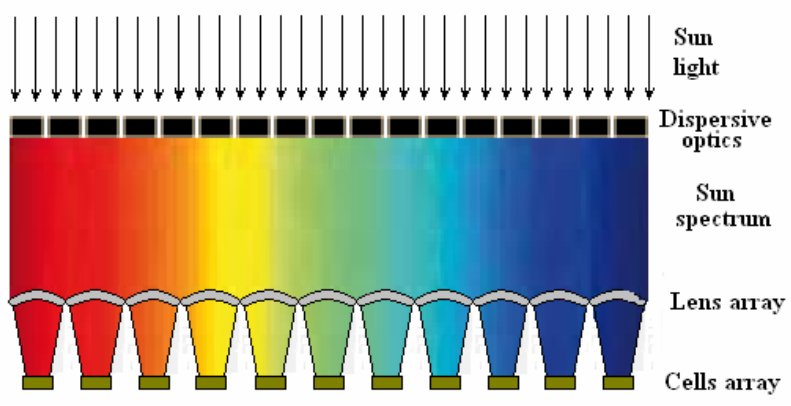

Fig. 2. Schematic design of a solar module with a lateral dispersion element operating on the transmission.

Potentially more attractive is the idea to manufacture solar modules of the lateral type (Fig. 2). In this case, the solar spectrum is proposed to split into several bands using dichroic elements (holographic gratings, dichroic mirrors, prisms) [10-14]. Light from each spectral interval is sent to the respective cell. This structure allows to minimize losses of the sunlight energy and to optimize solar cells for each spectral interval. In the experimental verification of performance of such structures (module with 5 cells and illumination of 20 suns), the obtained maximum efficiency is $\eta=42.9 \%$ [12].

In recent years, such printer technologies as screen printing, flexography (printing with stamps), engraving printing, offset lithography and inkjet printing are used to manufacture these solar modules and elements, including modules of the lateral type. From all these technologies, only inkjet printing allows one to create three-dimensional (3D) structures [15]. Inkjet printers are used for manufacturing the microelectronic elements: conductive tracks and coplanar waveguides [16], microelectromechanical systems, inductance coils, electrostatic motors [17] light-emitting diodes [18]. In the manufacture of solar cells, inkjet printers are used for forming metal contacts and interconnections of conductive tracks $[19,20]$.

In this work, we have carried out a research of the possibility to manufacture a lateral solar module using inkjet printer technology. The paper consists of two parts. The first one is a review of the current state of solar photoenergetics. It contains material relating to existing calculations for the limited efficiency of multijunction solar cells. Besides, we consider the factors and conditions for the possibility to manufacture the module type by using lateral inkjet printer technology. We briefly review the module architecture of the lateral type; properties of dispersive elements (interference filters, diffraction gratings) holographic focusing lenses, inkjet printers, ink, suitable for the formation of the elements of solar cells. The structure of the possible lateral module is proposed.

In the second part of the paper, we research more realistic approach, as compared to the existing ones, to 
estimate the limited efficiency of multiple $p-n$ junction solar cells. With computer simulation included, considered are such important effects as the cooling effect of multiple $p-n$ junction solar cells and the effect of shifting the energy range of solar radiation into the region of the absorption edge. Both of them are inhanced with increasing the number of cells. If the former effect leads to an increase of the photo-EMF and efficiency of phototransformation, the latter leads to a decrease in the photocurrent and efficiency of phototransformation. It is shown that, as a result of their joint action, the maximum attainable efficiency of phototransformation for $p-n$ junction solar cells has its peak with an increase in the number of cells.

We must point out that outside of this paper there remain technological aspects of the synthesis of nanoparticles with nanometer sizes, manufacturing inks with their cost analysis and application life, analysis of the possibility of manufacturing thick diffraction gratings with efficiency close to $100 \%$ within the spectral range $400-1700 \mathrm{~nm}$. We did not examine the characteristics of light concentrators. Outside this paper, there remain cost analysis for modules, panels, technical realization of tracking systems, methods of nondestructive testing the properties of cells at all stages of their production, from the deposition control of layer homogeneity, their annealing and finishing their encapsulating for protection from ambient factors.

\section{Lateral solar modules}

Any solar module consists of a set of electrically connected cells. Transformation of the sunlight energy into the electrical one takes place in the cells. In the lateral panel, each cell converts into electricity a narrow spectral interval of sunlight. To increase the intensity of light falling onto cells, concentrators are used. Below, we will study the properties of each module element and possible technology to manufacture it.

The design of a lateral solar module is schematically shown in Fig. 2. According to the principle of lateral solar module operation, sunlight falls on the dispersive element. It splits light into a spectrum. Different spectral bands are sent to a set of focusing lenses that focus the light onto the surface of solar cells. This means that every cell gets a given spectral interval of incident light. This allows to optimize each cell in order to achieve maximum efficiency of converting solar energy into electrical energy. Below, we will consider the properties of each element of the module and its manufacturing technology features.

\subsection{Dispersion element}

The main function of the dispersive element is splitting the sunlight into such minimum number of bands, which is sufficient to obtain the maximum efficiency of solar energy conversion into electricity. There are two variants of forming the bands. In the first case, the spectrum divider creates bands of large extension. Sunlight on each band is sent on mechanically folded stack of $p-n$ junctions or monolithic cells. In a second case, sunlight splitting into spectrum by diffraction grating (usually holographic grating). Spectral bands selected by holographic lenses. The size of the lens determines the width of the spectral interval sent to one or another cell.

\subsection{Interference filters}

The splitting of the solar spectrum into two or more spectral intervals can be achieved using multilayer dielectric mirrors or filters. Multilayer dielectric layers are deposited onto a thin glass plate. This plate is installed at the angle $45^{\circ}$ to the direction of propagating sunlight (Fig. 3a) [21]. The violet part of the spectrum is reflected from the plate and sent to the input surface of the first solar cell. The rest wavelengths passes through plate and fall onto the second solar cell. Each of these cells can be mechanically stacked or monolithic. These cells are optimized for maximum efficiency of converting the solar energy into electricity. Technical realization of solar module with dielectric mirror and two cells is shown in Fig. 3a [21]. Ultraviolet wavelengths $(\lambda<400 \mathrm{~nm})$ reflected by the mirror on AlGaAs cell and infrared wavelengths $(\lambda>780 \mathrm{~nm})$ pass through the plate and fall onto the polycrystalline silicon cell. The resulting efficiency reached by this solar converter is $19.3 \%$ [21]. In the case of separation of the solar spectrum into two parts and using GaInP/GaAs and InGaAsP/InGaAs cells, the total efficiency of individual cells and of the whole system equals, respectively, 31.8 and $29.2 \%$ [22].

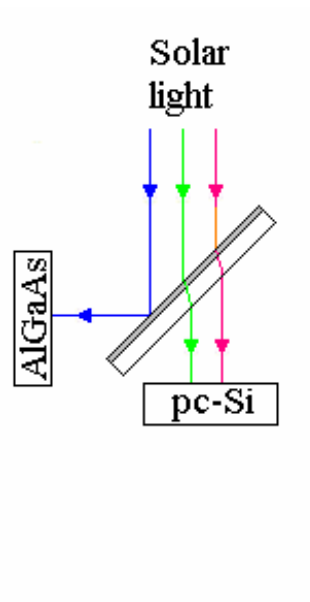

a

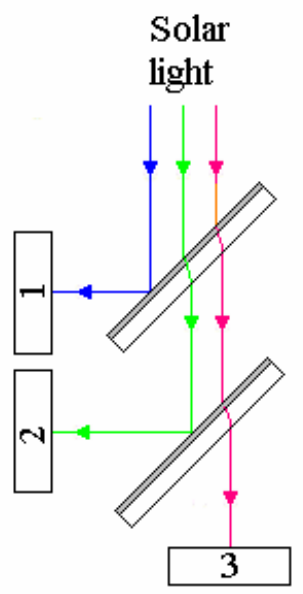

$\mathrm{b}$
Fig. 3. Schematic representation of the principle of separation of the solar spectrum band using one interference filter and two cells (a), two interference filters and three cells (b) (taken from [22]). 


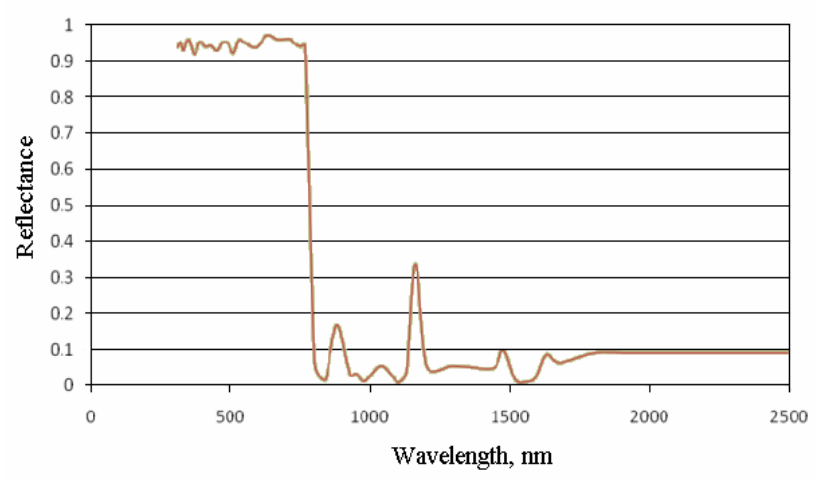

Fig. 4. Reflection spectrum of the interference filter (taken from [21]).

To increase the maximum efficiency, they use separation of the solar spectrum into several intervals. In particular, the use of two interference filters (Fig. 3b) allows to separate the solar spectrum into three intervals: $380-850,850-1100$, and $1100-1800 \mathrm{~nm}$ [14]. Light from the first interval falls onto Si cell with one $p-n$ junction, the second - onto GaSb cell with one $p-n$ junction, the third - onto the cell $\mathrm{Ga}_{0.51} \mathrm{In}_{0.49} \mathrm{P} / \mathrm{GaAs}$ with two $p-n$ junctions. The total efficiency of this lateral modulus is higher than $34 \%$ [14].

Using interference filters for the splitting of the spectrum, one obtains the following advantages. 1) The possibility of formation of spectral bands of step type (see Fig. 4). 2) Small losses of light $(<2 \%)$ in reflection from the filter in the $45^{\circ}$ geometry. The transmission filters exceed $90-95 \%$. 3) The possibility to separate narrow $(<30 \mathrm{~nm})$ bands at the filter output.

The disadvantages of the splitter are as follows. 1) The availability of polarization dependence of light that passes through the filter [23]. 2) Necessity using vacuum technology for the manufacture of filters. 3) Necessity to deposit a large number of dielectric layers. For example, for the formation of the step-like spectral characteristics within the region $380-850 \mathrm{~nm}$, depositing of 200 layers of $\mathrm{TiO}_{2}$ and $\mathrm{SiO}_{2}$ [14] is necessary. 4) The cost of interference filters is high. 5) The size of the operation surface in interference filters is limited.

\subsection{Diffraction gratings}

In the lateral type modules for the splitting of light into a spectrum, one can use diffraction (better holographic) gratings that operate as transmission or reflection elements (Fig. 5 [24]). For splitting light, in 1991 it was proposed to use a volume phase grating [25]). Such grating (with the thickness up to several tens of micrometers) is formed in a layer of transparent material (mainly in layer dichromatic gelatin). The gelatin film with the grating is placed between two plates of pure glass, silica or dielectric. In a narrow spectral band, the efficiency of volume gratings achieves $90-95 \%$. In a broader spectral range, the efficiency value (Fig. 6 [26]) is much lower and lies within the range between 40 to $70 \%[26,27])$. Manufacturing the volume grating is also known $([27,28])$. The main advantages of the volume grating are as follows: weak dependence of the efficiency on light polarization (Fig. 6), the possibility to manufacture gratings of large size up to $0.5 \mathrm{~m}^{2}$, sandwich structure of the volume grating provides protection from influence of the external environment and simplifies cleaning the surface grating structure. The main disadvantage of the volume grating is complicated manufacturing technology.

The main feature of the reflection grating is the strong dependence of the efficiency on light polarization (Fig. 7 [29]). The spectral region for reflection gratings with double blaze angle extends from 400 to $2500 \mathrm{~nm}$ (Fig. 8 [30]). Such a grating can get full sunlight. Features of gratings for reflection can be found in the works $([31,32])$. The main advantage of reflection grating is as follows: it possesses a greater width of the spectral region for the splitting of sun light. This grating is easy to replicate by stamping techniques with using a master grating. The disadvantage is a relatively low diffraction efficiency, which is dependent on light polarization.

\begin{tabular}{ll} 
& Volume \\
Relief & phase \\
reflection & holographic \\
grating & transmission \\
\hline & grating
\end{tabular}
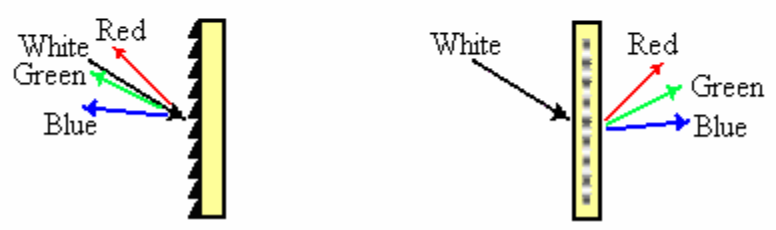

Fig. 5. Demonstration of the principle of diffraction grating operation on the reflection (left) and transmission (right) (taken from [24]).

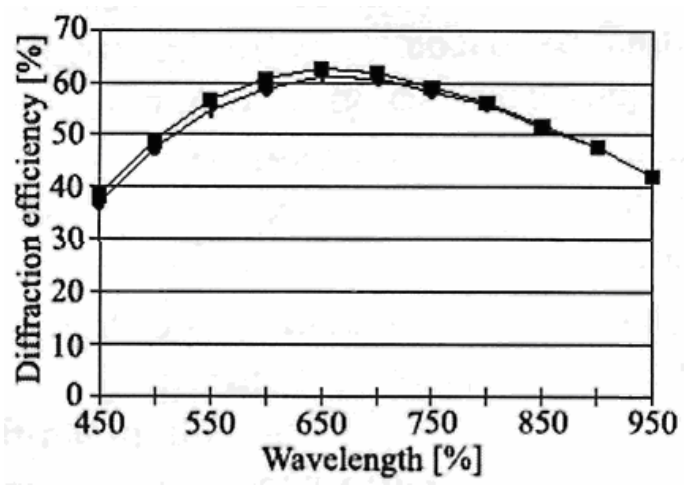

Fig. 6. Polarization dependence of the phase volume holographic gratings. The light polarization: $\mathbf{\square}$ - parallel, perpendicular (taken from [29]).

\section{(C) 2013, V. Lashkaryov Institute of Semiconductor Physics, National Academy of Sciences of Ukraine}




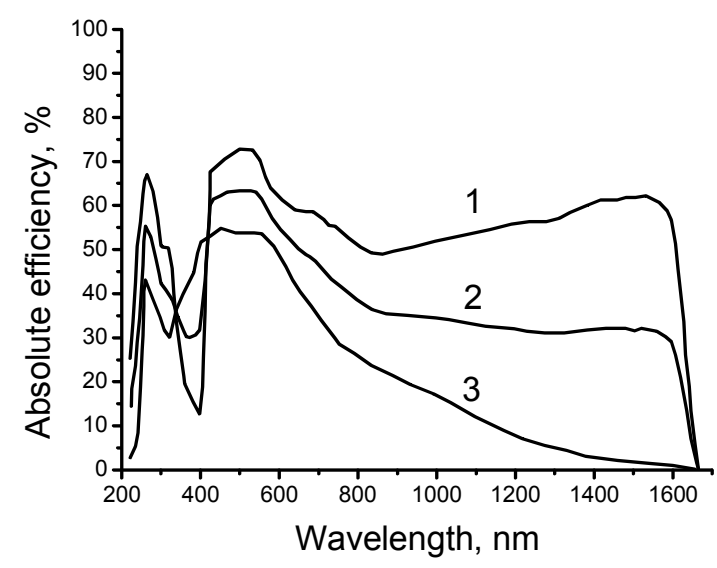

Fig. 7. Polarization dependence relief of the reflection grating operating in the reflection mode. Light polarization: 1 perpendicular, 2 - unpolarized, and 3 - parallel light (taken from [29]).

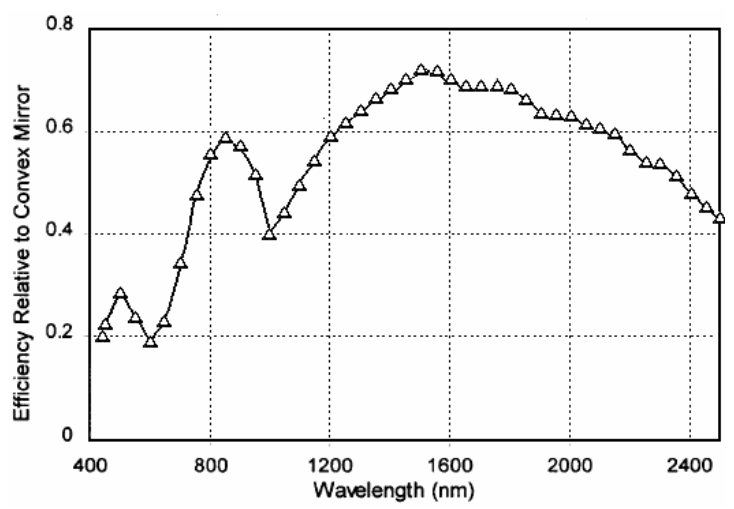

Fig. 8. The relative efficiency of the reflection grating with the double blaze angle. Within the range 400 to $1000 \mathrm{~nm}$, the spectral efficiency was measured in the second order, within the 1000-2500 $\mathrm{nm}$ range - in the first order (taken from [30]).

\subsection{Lenses}

The main function of lens is to focus certain parts of the solar spectrum on the input surface of the corresponding solar cells. In this case, an increased efficiency of solar cells is achieved and light losses caused by the necessity to lay power cables that connect cells in module and modules in the panel are decreased. Both holographic and refractive lenses can be fabricated by hot stamping of polymers (acrylic, silicone) or by cylindrical rolling [33] and by forming lenses by using inkjet printer [34]. The typical spectral efficiency of a lens array made from polymethylmethacrylate shown in Fig. 9 [35]. Within the range $400-800 \mathrm{~nm}$, the optical efficiency exceeds $80 \%$. Lenses form an ensemble that provides operation of the lateral solar converters.

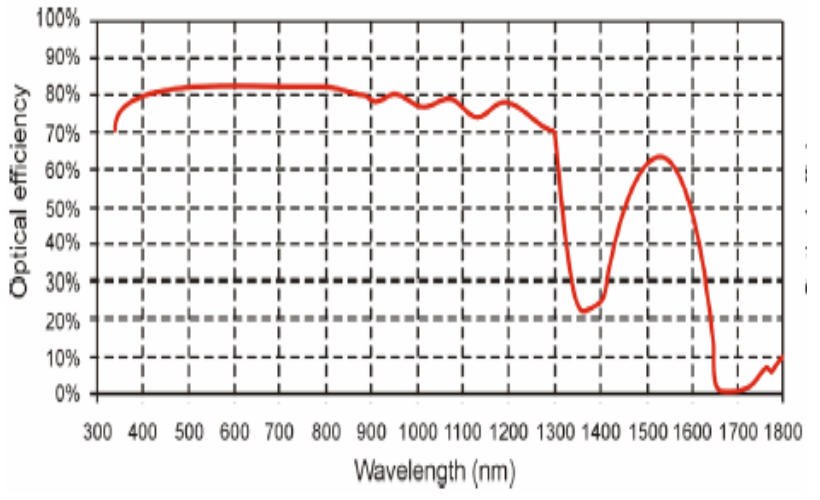

Fig. 9. Spectral dependence of the optical efficiency of the polymethylmethacrylate lens system (taken from [35]).

\section{Solar cells}

The main function of the solar cells is to convert solar energy from the given spectral interval into electrical energy with the highest possible efficiency. This occurs in $p-n$ or anisotype heterojunction. The efficiency of light energy conversion into electricity in cells with a $p-n$ junction is slightly higher compared to the cells with $p-i-n$ junction [36]. One must choose the construction and materials for solar cells in agreement with the following considerations.

1) If semiconductor material can be doped by donor and acceptor impurities, one can form the $p-n$ junction. If semiconductor have only electron or hole conductivity, one can form the anisotype heterojunction.

2) In most cases, holographic gratings concentrate light into the first order within the range 0.4 to $1 \mu \mathrm{m}$. This determines the choice of materials for forming solar cells. One can use diffraction gratings with two blaze angle to produce electricity from the energy of the whole solar spectrum.

3) A typical solar cell consists of several layers of different materials. In the simplest case, on the substrate one deposits consistently the layer of metal, semiconductor with a $p-n$ junction, a transparent conductive electrode and antireflection layer.

4) When manufacturing cells should give preference to non-vacuum, low-temperature technology deposition layers. But only inkjet technology allows to create a three-dimensional structure (3D technology) [15].

We must select the following milestones jet technology of solar cells. 1) Determination of the optimal number of cells to obtain maximum efficiency of solar module. 2) Development of ink to print $p$ and $n$ layers, the metal contacts, insulative and protective films. 3) Development of technology for deposition and annealing the ink used to form these elements. 4) Selection of an inkjet printer that can deposit these layers of materials. 


\subsection{Materials to form the solar cell}

In experimentally realized lateral converters of solar energy into electricity, solar cells fabricated using chemical vapor deposition (CVD) or metal-organic chemical vapor deposition (MOCVD) technologies are mainly used. The most promising technology is inkjet printer technology. Its use is based on the dependence of the melting temperature of the material on its size. Its existence follows from the thermodynamic model for clusters [37]. Solid body begins to melt when the amplitude of thermal vibrations of atoms exceeds the minimum distance between them. With decreasing the particle size, interaction of surface atoms with the bulk atoms decreases. As a result of increasing the amplitude of thermal fluctuations, the melting temperature of the particles decreases. Theories that describe the influence of particle size on their melting point differ from one another only due to assumptions about the mechanism responsible for weakening interaction of surface atoms with the bulk [38-40]. In particular, the typical dependence of the melting temperature of gold nanoparticles on size is shown in Fig. 10 [41]. In particular, such changes were observed by changing the particle size of silver [42], aluminum [43], platinum and palladium [44], tin [45], $\mathrm{ZnO}$ [40], $\mathrm{CdS}$ [46] and in a number of other materials. Analysis of these changes suggests that the melting point of the particles can be less than $300-400{ }^{\circ} \mathrm{C}$, when the size of nanoparticles is smaller than 3-5 $\mathrm{nm}$.

In the case of lateral solar modules, semiconductor nanoparticles of a mixed type (for example $\mathrm{Zn}_{\mathrm{x}} \mathrm{Pb}_{1-\mathrm{x}} \mathrm{S}$ ) and one-component (Ge, $\mathrm{Si}$ ) or two-component (for example semiconductors $\mathrm{A}^{2} \mathrm{~B}^{6}$ or $\mathrm{A}^{3} \mathrm{~B}^{5}$ type) can be synthesized. In the first case, the simplified separation of the spectrum into bands of desired width. However, in this case, you need to solve the problem to synthesize nanoparticles of nanometer size with a desired composition. In the second case, for the synthesis of However, in the case of single-component or twocomponent structures, the length of the spectral bands is rigidly defined.

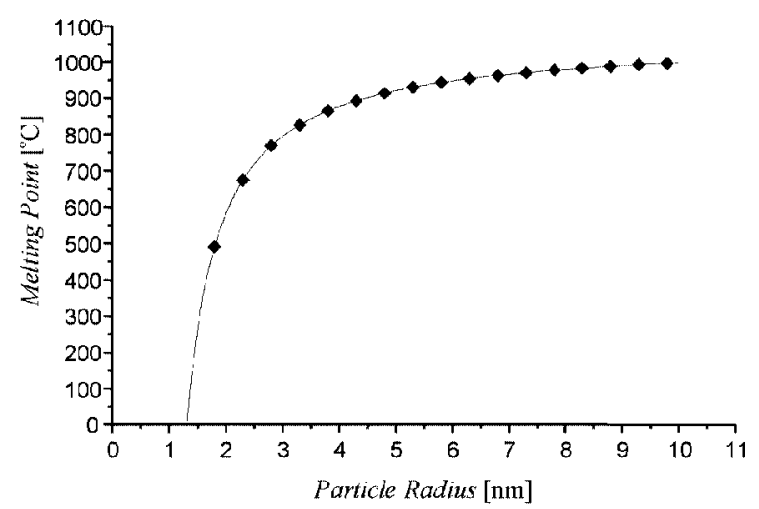

Fig. 10. Relationship between the particle size and melting point for gold nanoparticles (taken from [381).

\subsection{Ink for solar cells}

If liquid contains nanoparticles of metal, insulator, semiconductor, it could be designated ink. Droplets of small size (diameter from a few to several tens of micrometers) are deposited onto appropriate substrates, to form the desired pattern structure. After evaporation of liquid, they obtained a pattern of metal, semiconductor or dielectric structure. Parameters of the material structure, close to the parameters of the bulk material, we get after annealing of the structure. The required resistance of the deposited metal and semiconductor layers is achieved through the consiquent the deposition of several layers on each other [47].

It should be noted that only after annealing semiconductor ink semiconductor have properties of solid material. In the case of silicon, to manufacture highly efficient solar cells silicon must have a long lifetime of charge carriers. Obviously, inkjet printer technology inexpediently to use for getting this material. In direct-gap semiconductors, particularly group $\mathrm{A}^{3} \mathrm{~B}^{5}$, carrier lifetime is many orders of magnitude smaller than in silicon.

At a sufficiently high doping level, required to get a large photo-EMF value, radiative recombination must dominate in direct-gap semiconductors. In particular, in GaAs the carrier lifetime due to radiative recombination equals $5 \cdot 10^{-8} \mathrm{~s}$ for the doping level $10^{17} \mathrm{~cm}^{-3}$ and $5 \cdot 10^{-9} \mathrm{~s}$ for the doping level $10^{18} \mathrm{~cm}^{-3}$. These values are comparable with the lifetime for Shockley-Read recombination through the deep impurities. Taking into account the values of the lifetime and high values of light absorption coefficients in direct-gap semiconductors, inkjet technology can be used for manufacturing the solar cells made from these materials.

To provide the necessary properties of solar cells, the composition of ink must satisfy the following several rigorous requirements.

1. The size of metal or semiconductor nanoparticles should not exceed $3 \ldots 5 \mathrm{~nm}$. It is necessary to implement the annealing temperature of nanoparticles below the temperature of softening the plastic substrates and organic or inorganic insulating materials.

2. A liquid with nanoparticles should be solution with a maximum content of nanoparticles. You must provide an environment in which there is no deposition of nanoparticles on the bottom of the reservoir, i.e. to ensure homogeneity of the suspension.

3. The ink have additive compound to ensure isolation of nanoparticles and thus prevent their coagulation. It is desirable that these admixtures opposed oxidation of nanoparticles, which are not oxides. There are two types to stabilize the nanoparticles, namely: electrostatic and steric. According to classical colloidal science, formed around a charged particle is the double layer of electrically charged ions (Fig. 11), which prevents approach of nanoparticles and their 
coagulation [48]. Steric stabilization is provided by adsorption of polymer chains on the surface of nanoparticles (Fig. 11). When nanoparticles are approaching to each other, polymeric shells begin to interact and do not allow for nanoparticles to coagulate. To stabilize the nanoparticles that are in non-polar solvents, long alkyl chains (like trioles, amines or carboxylic acids) with polar head are used as anticoagulants [49].

4. Dispersant, i.e. additives, that reduce the viscosity of the ink, is introduced into ink composition. These can prevent nozzle clogging in the printer.

5. Adhesion activators, i.e. additives that promote formation of a strong bond of the coating with medium, to which the ink is applied, are introduced into ink. These prevent spreading the lines of picture structure and implement the ability to create three-dimensional structures.

6. Special additives in the ink composition promote connections between nanoparticles during the ink annealing.

7. Components of ink should be compatible to ensure their viability for a long time.

8. The ink should dry quickly, but not clog the nozzle and allow to clean it easy. To ensure a better quality of solar cells, the ink is overlay on the hot substrate. This ensures evaporation of the solvent and formation of a picture from surrounding anticoagulant nanoparticles.

9. Temperature sintering of ink (usually over $300^{\circ} \mathrm{C}$ ) should be sufficient for the destruction of organic additives that protect the nanoparticles from coagulation, and sufficient to stimulate association of nanoparticles in a continuous layer of metal, semiconductor or insulator $[49,50]$. Sintering can be performed by thermal heating, heating layer structure of laser light $[17,51]$, high temperature radio frequency plasma, by passing an electric current $[17,50,52]$.

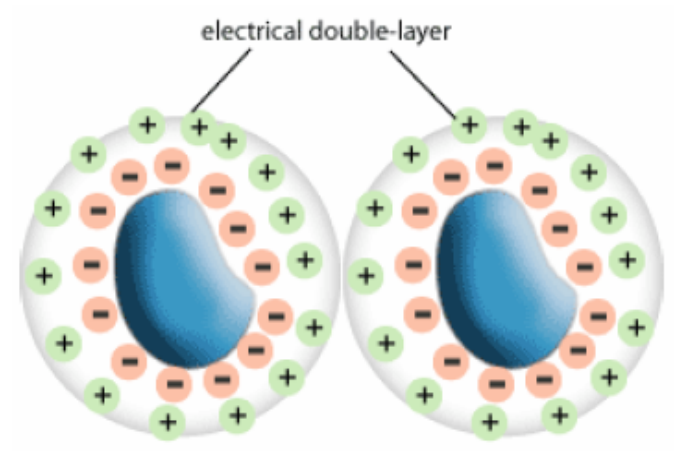

the formation of $p-n$ junction), plastic (they provide isolation between lines of the circuit and minimize leakage currents).

\subsubsection{Metal ink}

In microelectronic technology, to form contacts and circuit lines inks with gold can be used (the resistivity of the obtained gold coatings is only three to four times higher than that of bulk gold) [44, 53], silver (the resistivity obtained in silver coatings only 2 times higher than that of bulk silver) [47, 52-55], copper (the obtained resistivity of copper coatings 10 times higher than that of bulk copper) [55-58], nickel (the obtained resistivity of nickel coatings $\sim 10$ times higher than that of bulk nickel) $[59,60]$, aluminum (there observed extremely fast oxidation of deposited Al layers in air) [19].

With this brief review of metallic ink properties, we can conclude that, to form the conductive tracks and contacts, it is preferable to use Ag ink owing to their stability and low cost in manufacturing.

\subsubsection{Semiconductor inks}

The main purpose of this ink is formation of $p-n$ and $p-i-n$ junction solar cells. Up to date, already synthesized have been the following semiconductor inks with: Si [61, 62], ZnS [63, 64], ZnO [65, 66], ZnSe [67], Se [68, 69], CdS [70, 71], CdSe [72, 73], CdTe [74, 75], GaAs [76, 77], GaSb [78]. The Ge ink was not synthesized but Ge nanoparticles have been already synthesized [79].

\subsubsection{Insulators}

Used in manufacturing the solar cells is sintering most of the material at temperatures from 200 to $400{ }^{\circ} \mathrm{C}$. For this reason, insulating materials should remain stable at these temperatures. From all the variety of electrical insulating materials [80], the highest heat resistance is inherent to

Fig. 11. Model of electrostatic (left-hand) and of steric stabilization (right-hand) (taken from [48]).

Usually, the technical implementation of solar modules of lateral type required such ink: metal (they provide the formation of contacts and communication lines between solar cells), semiconductors (they provide polyimide films. These films are known as Kapton, Apical, Upilex. Polyimide films are incombustible, insoluble, have a greater resistance to acids, oils, organic solvents, have high thermal resistance up to $400{ }^{\circ} \mathrm{C}$. 
Polyimide films of the thickness 30, 40, 50, $60 \mu \mathrm{m}$ and width up to $1000 \mathrm{~mm}$ are produced in rolls with the minimum length up to $100 \mathrm{~m}$. Silver adhesion to these films is rather high. To isolate conductive silver lines by using inkjet printer, we can use polypirometylamidoacid solution in dimethylformamide (or dymetylatsetamitsidi) followed thermoimidesing. To form the insulating structures, one can use polyvinylpyrrolidone (PVP) ink in the following composition: water $-83 \%$, isopropyl alcohol $-4 \%$, PVP - 13\% [81, 82].

\section{Inkjet printers}

In the manufacture of solar cells, only inkjet technology allows one to create three-dimensional structures (3D technology) [82,83]. Principal advantages of inkjet technology are as follows: a low cost technology, highspeed manufacturing structures, low-temperature drying ink, low temperature annealing under heat or infrared light, or laser radiation, no need to use masks, easily automated, fewer restrictions on the choice of substrates and their morphology. The most powerful argument in favor of choosing inkjet technology for forming the structures of solar cells is a simple technology deposition of metal, semiconductor, dielectric layers (with parameters close to the parameters of bulk materials) at low melting temperatures, which simplified the selection of flexible substrates and insulating materials.

In manufacturing the microelectronic elements and solar cells, mainly used are piezoelectric inkjet printers of the drop type. For more expedient choice of the printer, one may use Table [84] that shows the characteristics of printers used to form elements of solar electronics. Also, a large number of printers (except listed in Table) are used for manufacturing different devices [85].

When manufacturing solar modules, the lateral type often needs cleaning substrates, acids and alkalines etching the metal and semiconductor layers. Therefore, in this case it is necessary to choose a printer with a sufficient amount of nozzles. As an example of a printer with a large number of nozzles in the print head, one can use the printer Trident's "256Jet-S TM" [86] with stainless steel head [87] and stainless steel diaphragm that isolates piezo elements from the liquid. The head of this printer with $100 \mathrm{~mm}$ width have 256 individually controlled nozzles.

Nozzles can be arranged in rows and columns in order to form an image of the structure by drops falling on the substrate. The printer has the ability to make one or more passes. This ensures the formation of the desired thickness of the structural elements and the formation of three-dimensional structure. The printer head can be heated up to $70^{\circ} \mathrm{C}$, providing partial evaporation of liquid ink. The printer is equipped with a laser, which allows locally heat the printed elements and materials to form components of cells with parameters close to the bulk parameters of relevant material.

\section{The possible variant of the lateral type of a solar module}

A solar module of the lateral type consists of three main blocks (Fig. 12): dispersion element, concentrator and array of solar cells. When you select each of these blocks, preference should be given to those that have lost solar minimum.

When choosing the dispersive element, we took into account: 1) absolute diffraction efficiency $\eta$ of dispersive element in the spectral region of sunlight should be as close to $100 \%$; 2) module with dispersion element should be compact; 3) manufacturing dispersive elements of large size must be proven and provide its automation. These requirements are satisfied in the best suited volume transmission gratings. The only lack is their relatively small spectral region, where $\eta$ is close to $100 \%$. However, in a sufficiently thick volume diffraction grating can be implemented sufficiently high diffraction efficiency within the spectral range from 400 to $1000 \mathrm{~nm}$. The possible implementation of gratings with high diffraction efficiency in the whole spectral

Table. Product data of the Galaxy, SX3 and DMC printheads (available from [84).

\begin{tabular}{|c|c|c|c|}
\hline Parameter & $\begin{array}{c}\text { Spectra Galaxy } \\
\text { PH 256/30 AAA }\end{array}$ & Spectra SX3 & $\begin{array}{c}\text { DMC-11601/ } \\
\text { DMC-11610 }\end{array}$ \\
\hline Number of addressable jets & 256 & 128 & 16 \\
\hline Nozzle spacing & $254 \mu \mathrm{m}$ & $508 \mu \mathrm{m}$ & $254 \mu \mathrm{m}$ \\
\hline Nozzle diameter & $36 \mu \mathrm{m}$ & $27 \mu \mathrm{m}$ & $9 \mu \mathrm{m} / 21.5 \mu \mathrm{m}$ \\
\hline Calibrated drop size & $28 \mathrm{pl}$ & $12 \mathrm{pl}$ & $1 \mathrm{pl} / 10 \mathrm{pl}$ \\
\hline Adjustment range for drop size & $25-30 \mathrm{pl}$ & $10-12 \mathrm{pl}$ & $\mathrm{N} / \mathrm{A}$ \\
\hline Drop size variation & $5 \%$ & $<2 \%$ & $3.5 \%$ \\
\hline Nominal drop velocity & $8 \mathrm{~m} / \mathrm{s}$ & $8 \mathrm{~m} / \mathrm{s}$ & $8 \mathrm{~m} / \mathrm{s}$ \\
\hline Drop velocity variation & $5 \%$ & $\pm 10 \%$ & $\mathrm{~N} / \mathrm{A}$ \\
\hline Operation temperature range & Up to $90^{\circ} \mathrm{C}$ & Up to $70^{\circ} \mathrm{C}$ & Up to $70^{\circ} \mathrm{C}$ \\
\hline Fluid viscosity range & $8-20 \mathrm{cP}$ & $10-14 \mathrm{cP}$ & $10-12 \mathrm{cP}$ \\
\hline Compatible jetting fluids & \multicolumn{3}{|c|}{ Organic solvents, UV curables, aqueous, acidic, basic } \\
\hline Maximum operating frequency & $20 \mathrm{kHz}$ & $10 \mathrm{kHz}$ & $80 \mathrm{kHz}$ \\
\hline
\end{tabular}

Note. UV - the flow of ultraviolet light. 
range of sunlight is not considered. Also, an additional analysis of manufacturing technology for such arrays is required.

The sheet which contains a volume grating is placed between two polymethylmethacrylate wafers (Fig. 12, dotted line) or between two other wafers of transparent material. At the bottom of the wafer, by using the hot stamping method one creates array of concentrators (Fig. 13), which do not form images. Its work is based on using the effect of total internal reflection. A part of rays directly falls to the bottom of the concentrator and therefore to the entrance surface of solar cells, and part of the side surface. Light falling on the side edge of the concentrator by total internal reflection is transported to the entrance surface of solar cells (Figs 12,13). For placing of conductive track and isolation of cells, it is enough to provide 2-3-fold concentration of light.

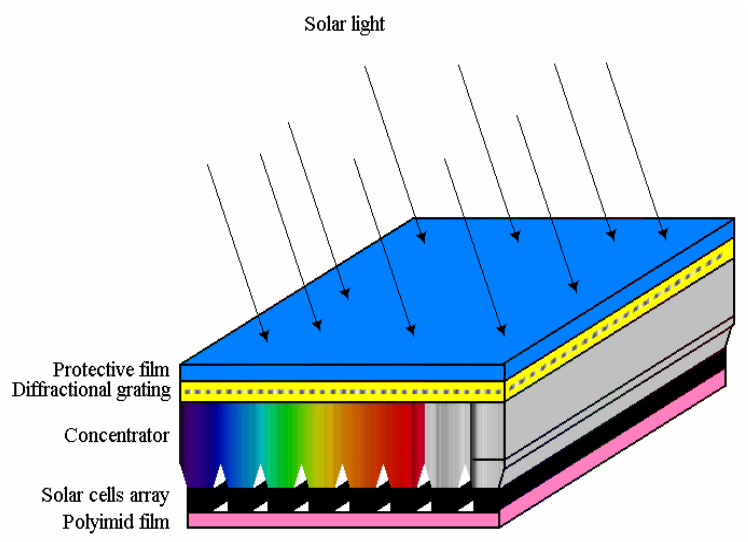

Fig. 12. Schematic design of a possible variant of a lateral solar module.

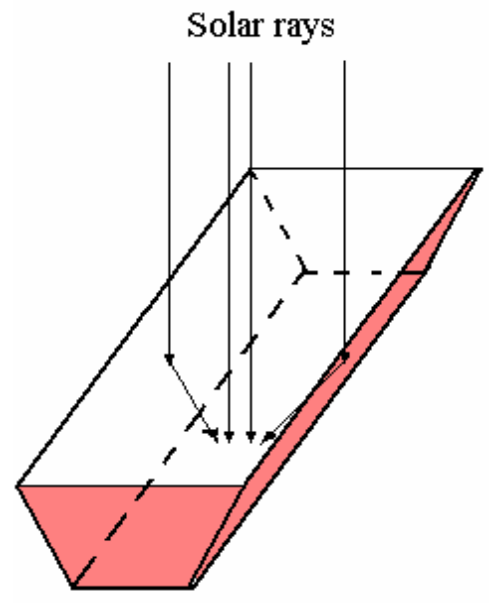

Fig. 13. One element of the concentrator for the solar module of the lateral type.
The array of solar cells can be produced as follows. The silver ink is used to form the contact layer and conductive tracks by inkjet printer (Fig. 14). On upper surface of the hot polyimide film the silver tracks and contacts are deposited using the same printer (Fig. 14). Metallic conductive tracks and contacts are formed after evaporation of solvent and annealing by laser light. Note that the operation of solvent evaporation and annealing performed at each stage of ink formation of a solar cell element. Then, the contact layers and tracks are insulated with polyimide coating. The array of contact layers is covered with polyimide ink. After annealing, the insulating layer is formed. Nickel ink is used to form an anti-diffusion layer on the silver contact. The polyimide insulating layer is deposited between contact pads. Further semiconductor $p$-type material is deposited on contact pads. Between pads, $p$-type semiconductor is deposited on polyimide insulating material. After the $p$ type material, deposited is the $n$-type material, forming a $p-n$ junction. Polyimide layers are deposited between semiconductor pads. Then, on the array of the $n$-type material pads, by suitable ink, deposited are transparent conductive contacts. The array of cells is attached with polymethylmethacrylate glue to array of concentrators. To protect the module from external factors, the upper face and the sides are covered with a transparent polymethylmethacrylate film.

\section{Simulation}

When estimating the efficiency of a solar module, it is usually considered that in every individual cell the efficiency is independent of that in other cells [3]. In this case, the efficiency of module is determined using the formula [88]

$\eta=\frac{\sum_{i}^{n} I_{m}^{i} V_{m}^{i}}{P_{S}}$,

where $I_{m}^{i}$ and $V_{m}^{i}$ are the maximum values of initial current and voltage, and $P_{S}$ is the power of sunlight. Following (1), it is possible to consider that generated in every individual cell is its own current. However, during technical realization of cells of vertical (mechanical or monolithic) or lateral (similar to that shown in Fig. 14) type elementary cells are connected in series. In these converters, the value of current is controlled by the cell in which the current is minimum [94]. The maximum efficiency will be realized then, when a current in all the cells is identical [95]. Below, we will define influence of a current matching on the efficiency of converters with many individual cells connected in series. We will execute our calculations under condition of AM0 illumination. The areas of all the elements are considered to be identical.

Foremost, it is necessary to note that, contrary to the approach of the work [3], in the course of 
calculations of the maximum efficiency for multijunction solar cells, it is necessary, at first, to refuse from the assumption that in every individual cell photoconversion takes place independently. Secondly, it is necessary to take into account that if the number of cells increases, the energy range of photons incident on each cell becomes more narrow. As a result, weight of the energy range with a decreased absorption coefficient is increased, and the temperature of each cell is reduced.

Therefore, as far as narrowing of energy interval the temperature of surface of concrete cell must decrease. In the case when heat conductivity of materials of individual cells is great, the same stationary temperature is set for all cells. For its finding it is needed to use the following balance equation:

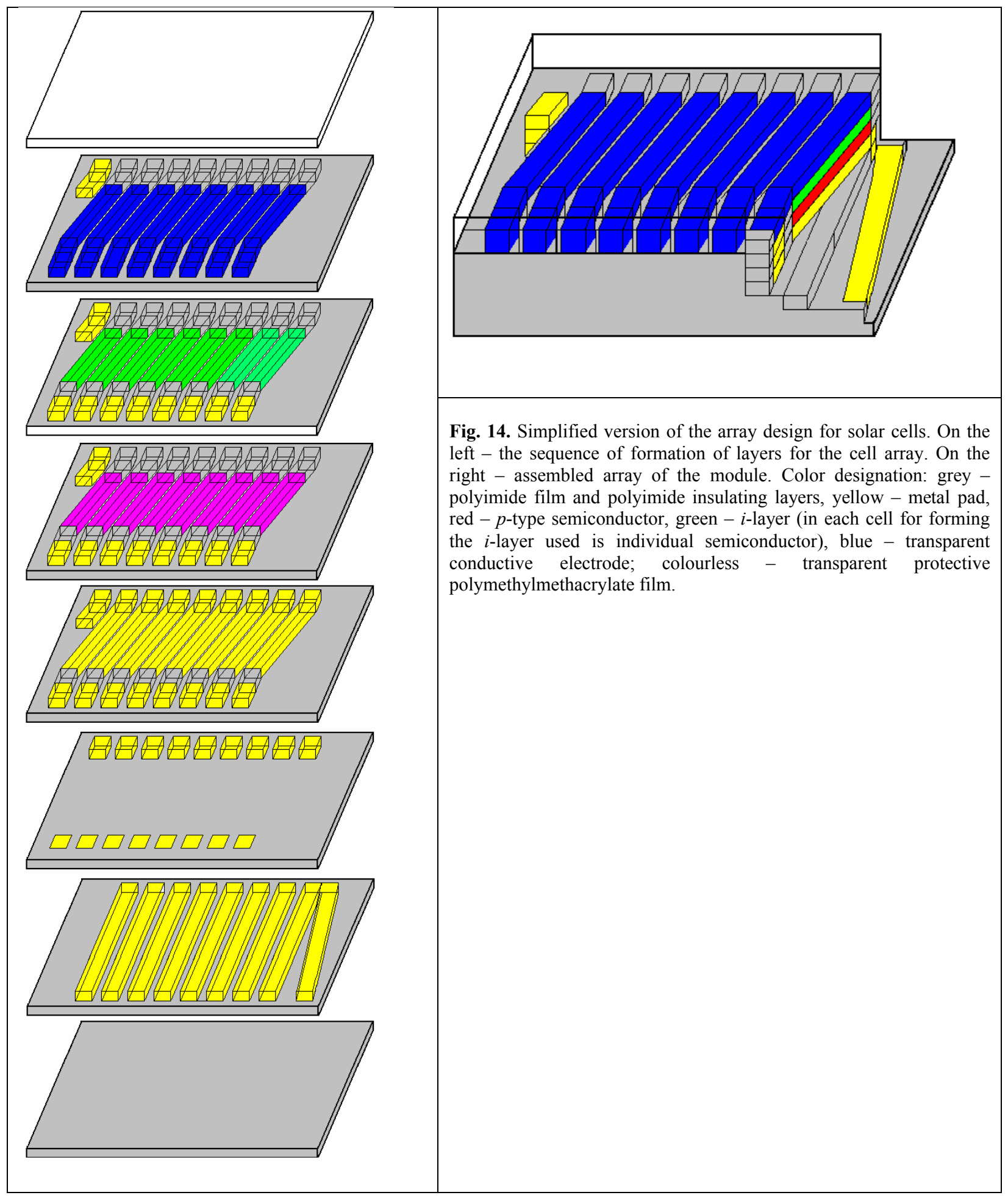

(C) 2013, V. Lashkaryov Institute of Semiconductor Physics, National Academy of Sciences of Ukraine 


$$
\int_{E_{1}}^{E_{2}} P\left(E_{f}\right) d E_{f}-J_{m}(T) V_{m}(T)=\beta \sigma T^{4} .
$$

Here $P\left(E_{f}\right)$ is the power density of solar radiation for a given photon energy; $E_{1}$ and $E_{2}$ are boundary energies of photons giving the entire spectrum absorbed by the multijunction solar cell; $J_{m}(T)$ and $V_{m}(T)$ are the specific density of the photocurrent and photovoltage at the maximum power extraction, respectively. For conditions AM1.5 $T=T_{\min }+\Delta T$, where $T_{\min }$ is the temperature of the environment, $\Delta T-$ excess of the total temperature $T$ as compared with $T_{\min }, \beta-$ a numerical factor of the order of unity. It depends on the proximity of the radiation surfaces in the solar cell to radiation of a black body. $\sigma$ is the Stefan-Boltzmann constant.

Note that in the case of a sequence of interconnected elements, the expression (1) is valid if all the multijunction solar cells are at the same temperature, i.e. in the case of sufficiently high thermal conductivity of individual elements and connections between them.

Let us obtain further expressions that define the relationship between the photocurrent and photovoltage in conditions of maximum power extracted when consecutively connected solar cells are matched by current. Here, we neglect the influence of the in-series resistance on the characteristics of the resulting solar cell. We will consider also the case when the faultiness factors for all the elements of the current-voltage characteristic (CVC) of multijunction solar cells are close to unity. This, in particular, corresponds to a situation when the dominant recombination channel is the radiative recombination one, and the excessive concentration of electron-hole pairs is much lower than the equilibrium concentrations of major carriers. We also assume that the inequality $d_{i}<<L_{i}$, where $d_{i}$ and $L_{i}$ are the thickness and length of the diffusion of nonequilibrium carriers for $i$-th cell, respectively. In this case, for the CVC of multijunction solar cells the approach [95] can be used. This yields the following expression for the open circuit voltage of cells in series

$V_{\text {sum }}=\sum_{i}^{n} E_{g i}+\frac{k T}{q} \sum_{i}^{n} \ln v_{i}$,

where

$$
v_{i}=\frac{J_{g}}{q d_{i} A_{i} N_{c 0 i} N_{v 0 i}\left(\frac{T}{300}\right)^{3}} .
$$

Here, $n$ is the number of a cells, $E_{g i}$ - band gap, $A_{i}$ - coefficient of radiative recombination, $d_{i}-$ thickness of a solar cell, and $N_{c 0 i}$ and $N_{v 0 i}$ - effective density of states in the conduction and valence bands for $i$-th cell. The value $J_{g}$ is equal to short-circuit current for current matched cells.

It was shown in [96] that between the short-circuit and photocurrent in the point of maximum power the following relations are fulfilled with a good accuracy:

$J_{m} \cong J_{g}\left(1-\frac{n k T}{q V_{\text {sum }}}\right)$

$V_{m} \cong V_{\text {sum }}\left(1-\frac{n k T \ln \left(q V_{\text {sum }} / n k T\right)}{q V_{\text {sum }}}\right)$.

We use these relations to determine the photoconversion efficiency for multijunction solar cells

$\eta=J_{m} V_{m} / P_{s}$,

where $P_{s}$ is the power of solar radiation falling on the solar cell.

We present further theoretical relations for the value of the short-circuit current. At the same time, we take into account the real value of the quantum yield of the photocurrent. Then,

$J_{g i}^{L}\left(E_{g i}\right)=s_{i} \int_{E_{g i}}^{E_{g i+1}} j_{g i}\left(E_{f}\right) q\left(E_{g i}, E_{f}\right) d E_{f}$,

where $s_{i}=S_{i} / S$ is the specific area factor of the $i$-th element, $j_{g i}\left(E_{f}\right)$ - photocurrent density for a given photon energy $E_{f}$ determined by the product of the electron charge $q$ and solar radiation flux density

$$
\begin{aligned}
& q\left(E_{g i}, E_{f}\right)=\frac{\alpha\left(E_{g i}, E_{f}\right) L_{i}}{1-\left(\alpha\left(E_{g i}, E_{f}\right) L_{i}\right)^{2}} \times\left[\frac{d_{i}}{L_{i}}+\alpha\left(E_{g i}, E_{f}\right) L_{i} \times\right. \\
& \left.\times \exp \left(-\alpha\left(E_{g i}, E_{f}\right) d_{i}\right)-\alpha\left(E_{g_{i}}, E_{f}\right) L_{i}\right],
\end{aligned}
$$

where $q\left(E_{g l}, E_{f}\right)$ is the quantum yield of photocurrent, $\alpha\left(E_{g i}, E_{f}\right) \quad-\quad$ light absorption coefficient, $L_{i}=\left(D_{i} / A_{i} n_{0}\right)^{1 / 2}-$ diffusion length of non-equilibrium minority carriers, $D_{i}$ - their diffusion coefficient, $n_{0}-$ doping level of the semiconductor.

Note that this expression for the quantum yield of the photocurrent is valid if inequality $L_{i} \gg d_{i}$ is fulfilled.

Thus, to find the function $\eta$ for the number of elements in the case of lateral multijunction solar cell design, it is necessary to solve the system of equations (2)-(8) with current matching. The latter condition corresponds to the case when the photocurrents of each element are equal, i.e. 


$$
J_{g 1}\left(E_{g 1}\right)=J_{g 2}\left(E_{g 2}\right)=\cdots=J_{g n}\left(E_{g n}\right)
$$

Then, let us continue the analysis of the values of minimum temperatures in the solar illumination conditions AM1.5 and AM0. Obviously, in AM1.5 the minimum temperature is the ambient one. Under AM0 conditions, mechanisms for heating and cooling of solar cells are pure radiation. So, the heating of solar cells occurs both through conversion into heat of the energy of solar spectrum and through absorption of heat that transferred from a satellite and solar light reflected from the satellite. We neglected influence on $T_{\min }$ the satellite thermal radiation associated with the heating of equipment of the operating satellite. In this work, all the calculations were performed for the case when the entire solar spectrum is absorbed by the solar cell. During calculations, we limited the spectral range of the solar spectrum by the wavelengths $0.3<\lambda<2 \mu \mathrm{m}$.

Shown in Fig. 15 is the dependence of the maximum achievable efficiency of photoconversion in lateral multijunction solar cells on the number of solar cells for the lighting conditions of AM1.5 and AM0. During the calculation, it was assumed that all the values $v_{i}$ are equal, and we used the following parameters: $A=2 \cdot 10^{-10} \mathrm{~cm}^{3} / \mathrm{s}, \quad D=50 \mathrm{~cm}^{3} / \mathrm{s}, \quad N_{c 0}=$ $5 \cdot 10^{17} \mathrm{~cm}^{-3}, \quad N_{v 0}=1 \cdot 10^{19} \mathrm{~cm}^{-3}, \quad d=2 \cdot 10^{-4} \mathrm{~cm}$, $n_{0}=10^{17} \mathrm{~cm}^{-3}, \beta=1$. It was assumed that as the elements of the lateral solar cells used are direct-gap semiconductors $\mathrm{A}^{3} \mathrm{~B}^{5}$ with arbitrary band gaps. As for the reference semiconductors, such as $\mathrm{GaP}, \mathrm{InN}$, $\mathrm{GaAs}, \mathrm{InP}, \mathrm{GaSb}$, radiative recombination constants and the effective mass of electrons and holes are very close, then it gives us the opportunity to consider all $v_{i}$ values to be equal to one another in this calculation.

Fig. 15 shows the dependence of the obtainable efficiency $\eta(n)$ of multijunction solar cells on the number of solar cells $n$ for the lighting conditions AM1.5 and $\beta=2$. This value is equal to $53.6 \%$. For the lighting conditions of AM1.5 and $\beta=2, \eta(n)=49.6 \%$. For $\beta=1$ the maximum $\eta(n)$ value for AM0 and AM1.5 are respectively equal to 48.7 and $47.2 \%$. The maximum efficiency are achieved when $n \approx 15$.

Recall that Fig. 15 was plotted using the assumption that, for any number of elements, these are optimized to the band gap of direct-gap semiconductors $\mathrm{A}^{3} \mathrm{~B}^{5}$. On the prima facie, this is true, since the use of ternary semiconductors $\mathrm{A}_{\mathrm{x}} \mathrm{B}_{1-\mathrm{x}} \mathrm{C}$ provides a range of semiconductors with continuously varying width of the bands, when the $x$ value is changed [13]. However, as shown by the detailed analysis, in the range $>2.0 \mathrm{eV}$ for semiconductors based on binary and ternary compounds that usually are indirect it requires a large $d$ value (approximately $100 \mu \mathrm{m}$ ), which makes it difficult to use them to create a lateral multijunction solar cell.

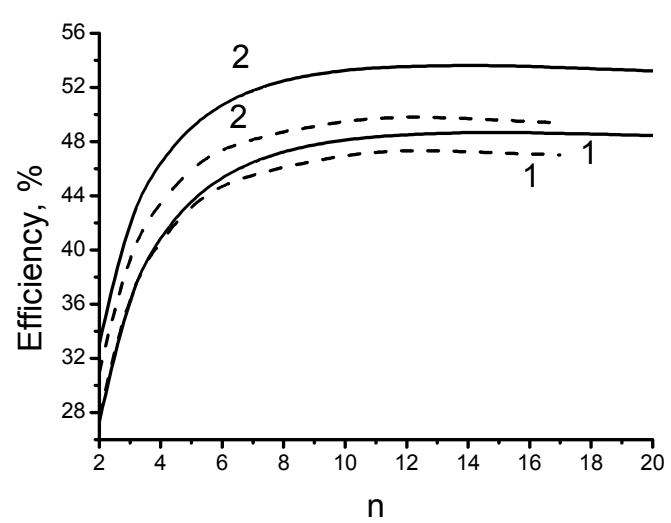

Fig. 15. Dependence of the efficiency on the number of cells. Curved line corresponds to the AM0 conditions, dashed line to the AM1.5 conditions. $\beta=1(1), \beta=2$ (1). Parameters of idealized semiconductor are used in these calculations.

So, it makes sense to get a dependence $\eta(n)$ using the parameters of the existing direct-gap semiconductors. In this case, the current matching in different solar cells means to reduce the efficiency.

The results of this simulation are shown in Fig. 16. As one can see, in this situation the value of the efficiency is quite strongly reduced as compared with the first (idealized) case, and its sharp maximum is attained at a small number of $n$ ( 4 for AM0 and 5 for AM1.5). The result will depend on the choice of specific semiconductors, but the qualitative picture does not change.

Fig. 16 shows the theoretical dependence $\eta(n)$ calculated using parameters of the existing direct-gap semiconductors. During calculation of curves 1 and 3 , we used $\beta=2$, while for curves 2 and 4 we used $\beta=1$. In the first case, the temperature is lower, and the efficiency is higher. The maximum values of $\eta(n)$ are reached for $n=4$. For AM0 and $\beta=2, \eta_{\max }=45.1 \%$. Shown in the insert to Fig. 16 is the theoretical dependence for AM1.5 and experimental dependences taken from [97-100]. As seen from the figure, we calculated the theoretical dependence sufficiently close to the experimental values.

The results of this approach, in principle, differ from the traditional estimates for the influence of the number of solar cells on the efficiency of photoconversion of solar energy to electricity (see, for example, $[3,11]$ ). The maximum photoconversion efficiency is calculated by us in sufficiently real assumptions taking into account, in particular, dependences of open-circuit voltage and factor of filling of current-voltage characteristic on the level of doping the semiconductor. The unique simplification is the assumption that the main recombination channel is the radiative recombination one, rather than Shockley-Read recombination. Since for direct-gap semiconductors we use assumptions close to reality, the resulting maximum efficiency is much closer to reality than the value of $63.2 \%$ obtained in [11] 


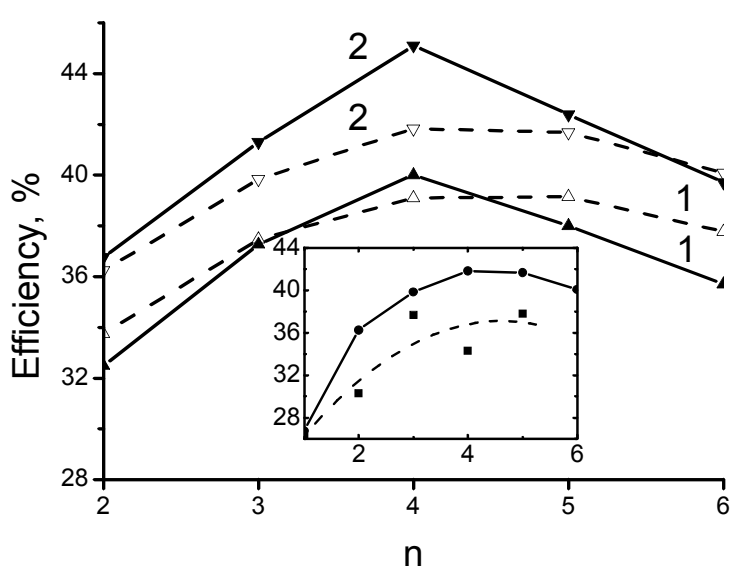

Fig. 16. Dependences of the efficiency on the number of solar cells. The set of $\mathrm{GaSb}, \mathrm{GaAs}_{0.7} \mathrm{Sb}_{0.3}, \mathrm{GaAs}, \mathrm{Al}_{0.15} \mathrm{Ga}_{0.85} \mathrm{As}$, $\mathrm{Al}_{0.3} \mathrm{Ga}_{0.7} \mathrm{As}, \mathrm{Al}_{0.45} \mathrm{Ga}_{0.55} \mathrm{As}$ is used for combinations of cell materials. Curved line corresponds to the conditions AM0, dashed line - to the conditions AM1.5. $\beta=1(1), \beta=2(1)$.

The insert: comparison of the calculated and experimental dependences of the efficiency on the number of solar cells. Experimental values for the efficiency were taken from the papers [97-100]. The curved line corresponds to the conditions AM1.5. $\beta=1(1)$, dashed line - experiment.

\section{Conclusions}

Today, conditions for making the monolithic lateral photoconverter that consists of a dispersion element, concentrator and array of the elementary cells connected in series are created.

From all of the types of dispersion elements (prisms, holographic gratings, multilayered dielectric dividers of spectrum) only thick transmission holographic grating capable to provide compactness. The diffraction efficiency of such a grating in a narrow spectral range is close to $100 \%$. Analysis of the possibility to make thick holographic gratings with the maximum possible efficiency within the spectral region of sun radiation is quite necessary. Such grating needs to be placed between plates from transparent dielectric (for example, polymethylmethacrylate or vinyl). An overhead plate safeguard solar cell. On a lower plate, hot pressing forms the array of concentrators. In this case, a dispersion element forms a combine unit with the array of concentrators. The coefficient of light concentration gets out small values $(1.5 \ldots 2)$, sufficient for the lay of electrical line links between cells and for providing isolation between cells. To provide equal number of light quanta on the output of every concentrator, their entrance areas are optimized, and output areas are made identical.

In accord with the results of simulation for the solar cells connected in series at a certain choice of solar cells, the maximum efficiency can be obtained at the level $45 \%$. In the case of specific semiconductors, the value $\eta(n)$ is much lower $(\approx 42 \%)$ and has a maximum at $n \approx 5$. In this case, calculation results are consistent with experiment. However, it is necessary to optimize selection of materials for cells and to study its impact on the value of efficiency in equal numbers of light quanta incident on the input surface of each cell.

For making the array of cells, the most perspective is inkjet technology that is able to form threedimensional structures. Industry produces the inkjet printers of various modifications. Their modernization is needed only to form arrays of solar cells.

To use three-dimensional technology for formation of solar cells, it is necessary to have a set of inks to form contacts and conductive tracks, semiconductor and isolating layers.

Currently, inkjet technology is already used for manufacturing the elements of solar cells (see, for example, [84,91]). The following technological operations are already used: 1) deposition (with the use of silicon inks) of silicon layers of $n$-type on silicon substrates of $p$-type $[84,91]$; 2) doping the silicon layer with a donor type impurity in the process of its deposition [84]; 3) deposition of a protective dielectric layer $[84,91]$; 4) etching the dielectric and silicon layers [97]; 5) deposition of metallic contacts (a silver [91-93] contact with a nickel thin-film adhesion layer [94]) on the entrance and rearward surface of a silicon solar cell; 6) deposition of transparent conductive contacts (semiconductors of $\mathrm{ZnO}, \mathrm{SnO}_{2}$ ) [93].

Nowadays, majority of solar cells are manufactured using the method of the screen printing [84]. Today the efficiency of such silicon solar cells is close to $17 \%$ $[84,91]$. In the National Laboratory of Renewable Energy of the USA, in standard screen printing technology, operations of the local deposition of dopant for creation strongly doped under-contact areas in the high-performance selective emitters deposition of $n$-type silicon on silicon substrate of $p$-type and deposition of silver contacts were replaced by inkjet operations of these materials. Changed in this manner technology enabled to produce 15000 solar cells. The average efficiency equals $18.6 \%$ [91]. Consequently, it is possible to expect transfer to fully inkjet technology of manufacturing the solar cells in the nearest future.

\section{References}

1. P.T. Landsberg, V. Badescu, Solar energy conversion: list of efficiencies and some theoretical considerations. Part I - Theoretical considerations // Progress in Quantum Electronics, 22(4), p. 211230 (July 1998).

2. P.T. Landsberg, V. Badescu, Solar energy conversion: List of efficiencies and some theoretical considerations. Part II - Results // Progress in Quantum Electronics, 22(4), p. 231255 (July 1998).

3. V.A. Green, Third Generation Photovoltaic: Advanced Solar Energy. Springer, New York, 2003. 
4. W. Shockley and H.J. Queisser, Detailed balance limit of efficiency of $\mathrm{p}-\mathrm{n}$ junction solar cells // $J$. Appl. Phys. 32(3), p. 510-519 (1961).

5. C.H. Henry, Limiting efficiencies of ideal single and multiple energy gap terrestrial solar cells // J. Appl. Phys., 51, p. 4494 (1980).

6. M.A. Green, K. Emery, Y. Hishikawa, W. Warta, Solar cell efficiency tables (version 37) // Progress in Photovoltaics: Research and Applications, 19, p. 84-92 (2011).

7. S. Yoon, V. Garboushian, D. Roubideaux, Reduced temperature dependence of high-concentration photovoltaic solar cell open-circuit voltage $\left(\mathrm{V}_{\mathrm{oc}}\right)$ at high concentration levels // IEEE First World Conf. on Photovoltaic Energy Conversion, Conference Record of the 24th IEEE Photovoltaic Specialists Conf., vol. 2, p. 1500-1504 (1994).

8. A.Q. Malik, Lim Chee Ming, Tan Kha Sheng and M. Blundell, Influence of temperature on the performance of photovoltaic polycrystalline silicon module in the Bruneian climate // ASEAN J. on Science \& Technology for Development (AJSTD), 26(2), p. 61-72 (2010).

9. G. Landis, D. Merritt, R.P. Raffaelle, D. Scheiman, High-temperature solar cell development // 18th Space Photovoltaic Research and Technology Conf., p. 241-247 (2005). Report number: NASA/CP-2005-213431.

10. Photovoltaics take a load off soldiers // http/www.solar.udel.edu/CSOctSOL-Darpareprint.pdf.

11. A. Barnett, C. Honsberg, D. Kirkpatrick, et al., $50 \%$ efficient solar cell architecture and designs // IEEE $4^{\text {th }}$ Word Conf. Photovoltaic Energy Conversion. vol. 2, p. 2560-2564 (2006).

12. A. Barnett, D. Kirkpatrick, C. Honsberg et al., Milestones toward 50\% efficient solar cell modules $/ / 22^{\text {nd }}$ Europ. Photovoltaic Solar Energy Conf., Milan, Italy, September 3, 2007, p. 1 - 6.

13. D.A. Caselli, C.Z. Ning, High-performance laterallyarranged multiple bandgap solar cells using spatially compositiongraded $\mathrm{Cd}_{\mathrm{x}} \mathrm{Pb}_{1-\mathrm{x}} \mathrm{S}$ nanowires on a single substrate: a design study // Opt. Exp. 19(S4), p. A686-A6944 (July 2011); J.I. Alferov, V.M. Andreev, V.D. Rumiantsev Tendencies and perspectives development of solar photo energetics // Fizika i teknika poluprovodnikov, 38(8), p. 937-947 (2004), in Russian.

14. B. Mitchell, G. Peharz, G. Siefer et al., Fourjunction spectral beam-splitting photovoltaic receiver with high optical efficiency // Progress in Photovoltaics: Research and Applications, 19, p. 61-72 (2011).

15. U. Caglar, Studies of printing technology with focus on electronic materials // Thesis for the degree of Doctor of Technology. Tampere University of Technology. Tampere, Finland, 2009.
16. O. Azucena, J. Kubby, D. Scarbrough, C. Goldsmith, Inkjet printing of passive microwave circuitry // Microwave Symposium Digest 2006 IEEE MTT-S Intern. p. 1075-1078 (2008).

17. S.B. Fuller, E.J. Wilhelm, J.M. Jacobson, Ink-jet printed nanoparticle microelectromechanical systems // J. Microelectromech. Systems, 11(1), p. 1-7 (February 2002).

18. A. Gopal, K. Hoshino, S. Kim, X. Zhang, Microcontact printing of multicolor quantum dots light emitting diode on silicon // Conf. on Lasers and Electro-Optics, Baltimore, Maryland, USA (2009), p.1-2 .

19. A. Kamyshny, J. Steinke, S. Magdassi, Metal-based inkjet inks for printed electronics // The Open Appl. Phys. J., 4, p. 19-36 (2011).

20. T. Kaydanova, A. Miedaner, C. Curtis, J. Perkins, J. Alleman, D. Ginley, Ink jet printing approaches to solar cell contacts // National Center for Photovoltaics and Solar Program Review Meeting, Denver, Colorado March 24-26, 2003.

21. A. Mokri, M. Emziane, Beam-splitting versus tandem cell approaches for converting the solar spectrum into electricity: A comparative study // Intern. Renewable Energy Congress IREC2010, Sousse, Tunisia, November 5-7, 2010, p. 76 - 79.

22. K. Xiong, S. Lu, J. Dong, T. Zhou, D. Jiang, R. Wang, H. Yang, Light-splitting photovoltaic system utilizing two dual-junction solar cells // Solar Energy, 84, p. 1975-1978 (2010).

23. Dichroic laser mirrors. The unitary enterprise of "Aksikon", National Academy of Sciences of Republic of Belarus, Minsk (2002).

24. Volume Phase Gratings (VPGTM) // ® BaySpec, Inc. White Paper. 11/20/2002, p. 1 - 4 .

25. J.E. Ludman, Photovoltaic Systems Based on Spectrally Selective Holographic Concentrators // Final Report for Period May 1991 to December 1991. Aero Propulsion@ Power Directorate Wright Laboratory Air Force Materiel Command Wright Patterson Air Force Base, Ohio 45433-6563.

26. M. Aiko, Hyperspectral prism-grating-prism imaging spectrograph // Technical research centre of Finland. Finland, ESPOO 2001, p. 1-125.

27. S.C. Barden, J.A. Arns, W.S. Colburn, Volumephase holographic gratings and their potential for astronomical applications, in: Optical Astronomical Instrumentation, Ed. S. D'Odorico // Proc. SPIE, 3355, p. 866 (1998).

28. P.-A. Blanche, P. Gailly, S. Habraken, P. Lemaire, C. Jamar, Volume phase holographic gratings: large size and high diffraction efficiency // Opt. Eng. 43(11), p. 2603-2612 (2004).

29. Introduction to Diffraction Grating - thorlabs.com // www.thorlabs.com.

30. P.D. Maker, R.E. Muller, D.W. Wilson, P. Mouroulis, New convex grating types manufactured by electron beam lithography // 
Diffractive Optics and Micro-Optics, 10, p. 234236 (1998).

31. C. Palmer, Diffraction Grating, Handbook. Sixth edition. Newport Corporation, 2005.

32. Scientific diffraction grating/Castom grating. Product catalog and capabilities // www.jobinyvon.com

33. M.T. Gale, C. Gimkiewicz, S. Obi, M. Schnieper, J. Sochtig, H. Thiele, S. Westenhofer, Replication technology for optical microsystems // Opt. and Lasers in Eng. 43, p 373-386 (2005).

34. J.Y. Kim, N.B. Brauer, V. Fakhfouri, D.L. Boiko, E. Charbon, G. Grutzner, J. Brugger, Hybrid polymer microlens arrays with high numerical apertures fabricated using simple ink-jet printing technique // Opt. Mater. Exp. 1(2), p. 259-269 (2011).

35. E. Brinksmeier, A. Gessenharter, D. Pérez, J. Blen, P. Benítez, V. Díaz, J. Alonso, Design and manufacture of aspheric lenses for novel high efficient photovoltaic concentrator modules // Proc. ASPE 19th Annual Meeting, Orlando, Florida, USA, October 24-20, 2004, p. 582-585.

36. T. Kirchartz, Generalized detailed balance theory of solar cells // Von der Fakultat fur Elektrotechnik und Informationstechnik der RheinischWestf alischen Technischen Hochschule Aachen zur Erlangung des akademischen Grades eines Doktors der Ingenieurwissenschaften genehmigte Dissertation. 6 Februar 2009, p. 1 - 203.

37. I.P. Suzdalev, Nanotechnology: Physics-Chemistry of Nanoclusters, Nanostructures and Nanomatters. KomKniga, Moscow, 2006 (in Russian).

38. P. Buffat, J.P. Borel, Size effect on the melting temperature of gold particles // Phys. Rev. A, 13, p. 2287-2298 (1976).

39. J. Yanfeng, Z. Yamin, Influence of gold particle size on melting temperature of VLS grown silicon nanowire // J. Semiconductors, 31(1), 012002-1 012002-5 (2010).

40. G. Guisbiers, S. Pereira, Theoretical investigation of size and shape effects on the melting temperature of $\mathrm{ZnO}$ nanostructures // Nanotechnology, 18, 435710 (6p.), (2007).

41. G. Schmid, B. Corain, Nanoparticulated Gold: Syntheses, Structures, Electronics, and Reactivities // Eur. J. Inorg. Chem. 17, p. 3081-3098 (2003).

42. Z. Radivojevic, K. Andersson, K. Hashizume, M. Heino, M. Mantysalo, P. Mansikkamaki, Y. Matsuba, N. Terada, Optimised curing of silver ink jet based printed traces // Dans Proc. $12^{\text {th }}$ Intern. Workshop on Thermal Investigations of ICs THERMINIC 2006, Nice, France (2006). arXiv:0709.1842 [cond-mat.mtrl-sci].

43. J. Sun, S.L. Simona, The melting behavior of aluminum nanoparticles // Thermochimica Acta, 463, p. 32-40 (2007).

44. G. Guisbiers, G. Abudukelimu, D. Hourlier, Sizedependent catalytic and melting properties of platinum-palladium nanoparticles // Nanoscale Res. Lett. 6(1), p. 396 (2011).

45. S.L. Lai, J.Y. Guo, V. Petrova, G. Ramanath, L.H. Allen, Size-dependent melting properties of small tin particles: Nanocalorimetric measurements // Phys. Rev. Lett. 77(1), p. 99-102 (1 July 1996).

46. S. Griffith, Towards personal fabricators: Tabletop tools for micron and sub-micron scale functional rapid prototyping // Thesis degree of Master of Science in Media Arts and Sciences at the Massachusetts Institute of Technology, February 2001.

47. M.F.A.M. van Hest, C.J. Curtis, A. Miedaner, R.M. Pasquarelli, T. Kaydanova, P. Hersh, and D.S. Ginley, Direct-write contacts: Metallization and contact formation // 33rd IEEE Photovoltaic Specialists Conf., San Diego, California, May 1116, 2008.

48. A. Mette, New Concepts for Front Side Metallization of Industrial Silicon Solar Cells // Dissertation zur Erlangung des Doktorgrades der Fakultät für Angewandte Wissenschaften der Albert-Ludwigs-Universität Freiburg im Breisgau, 2007.

49. J. Perelaer, A.W.M. de Laat, C.E. Hendriksa, U.S. Schubert, Inkjet-printed silver tracks: low temperature curing and thermal stability investigation // J. Mater. Chem., 18, p. 3209-3215 (2008).

50. J. Perelaer, U.S. Schubert, Inkjet printing and alternative sintering of narrow conductive tracks on flexible substrates for plastic electronic applications // Radio Frequency Identification Fundamentals and Applications, Design Methods and Solutions. Ed. C. Turcu. INTECH, Croatia, downloaded from SCIYO.COM.

51. J. Chung, S. Ko, C.P. Grigoropoulos, N.R. Bieri, C. Dockendorf, D. Poulikakos, Microconductors on polymer by nanoink printing and pulsed laser curing // Proc. HTFE'04 2004 ASME Heat Transfer/Fluids Eng. Summer Conf. Charlotte, North Carolina, July 11-15, 2004 HT-FED200456702.

52. M.L. Allen, M. Aronniemi, T. Mattila, A. Alastalo, K. Ojanpera, M. Suhonen, H. Seppa, Electrical sintering of nanoparticle structures // Nanotechnology, 19, 175201 (2008).

53. J. Chung, S. Ko, C.P. Grigoropoulos, N.R. Bieri, C. Dockendorf, D. Poulikakos, Damage-free low temperature pulsed laser printing of gold nanoinks on polymers // J. Heat Transfer, 127, p. 724-732 (July 2005).

54. S.M. Bidoki, D.M. Lewis, M. Clark, A. Vakorov, P.A. Millner, D. McGorman, Ink-jet fabrication of electronic components // J. Micromech. Microeng. 17, p. 967-974 (2007).

55. C. Curtis, T. Rivkin, A. Miedaner, J. Alleman, J. Perkins, L. Smith, D. Ginley, Metallizations by direct-write inkjet printing. Preprint // NCPV 
Program Review Meeting, Lakewood, Colorado, October 2001, p. 14-17.

56. J.S. Kang, J. Ryu, H.S. Kim, H.T. Hahn, Sintering of inkjet-printed silver nanoparticles at room temperature using intense pulsed light // $J$. Electron. Mater. 40(11), p. 2268-2277 (2011).

57. B.K. Parka, D. Kim, S. Jeong, J. Moon, J.S. Kim, Direct writing of copper conductive patterns by ink-jet printing // Thin Solid Films, 515, p. 77067711 (2007).

58. K.F. Teng, R.W. Vest, Application of inkjet technology on photovoltaic metallization // IEEE Electron. Device Lett. 9(11), p. 591-592 (1998).

59. Y. Qi, T. Cagin, Melting and crystallization in $\mathrm{Ni}$ nanoclusters: The mesoscale regime // J. Chem. Phys., 115(1), p. 385-3941 (July 2001).

60. C.J. Curtis, M. van Hest, A. Miedaner, T. Kaydanova, L. Smith, and D.S. Ginley, Multi-layer inkjet printed contacts to Si // 2005 DOE Solar Energy Technologies Program Review Meeting, Denver, Colorado, November 7-10, 2005.

61. H. Antoniadis, Silicon ink high efficency solar cells // $34^{\text {th }}$ IEEE Photovoltaic Spesialists Conference (PVSC), Philadelphia, USA, 2009, p.131-134.

62. A. Gupta, A.S.G. Khalil, M. Winterer, H. Wiggers, Stable colloidal dispersion of luminescing silicon nanoparticles for ink-jet printing // Nanotechnology, 2, p. 538-541 (2010).

63. J.P. Borah, J. Barman, K.C. Sarma, Structural and optical properties of $\mathrm{ZnS}$ nanoparticles // Chalcogenide Lett. 5(9), p. 201-208 (2008).

64. J.H. Johnston, A.C. Smalla, N. Clarkb, Colour tuneable photoluminescent quantum dots for ink-jet printing of security documents and labels // Chemistry in New Zealand, 74, p. 70-71 (April 2010).

65. Hao Wei, Meng Li, Zichao Ye, Zhi Yang, Yafei Zhang, Novel Ga-doped $\mathrm{ZnO}$ nanocrystal ink: Synthesis and characterization // Mater. Lett. 65, p. 427-429 (2011).

66. S.T. Meyers, J.T. Anderson, C.M. Hung, J. Thompson, J.F. Wager, D.A. Keszler, Aqueous inorganic inks for low-temperature fabrication of ZnO TFTs // J. Amer. Chem. Soc. 130, p. $17603-$ 17609 (2008).

67. M. Shakira, Siddhartha, G. Bhagavannarayana, M.A. Wahab, Structural, optical and electrical properties of $\mathrm{ZnSe}$ semiconductor nanoparticles // Chalcogenide Lett. 8(7), p. 435-440 (2011).

68. G. Fracasso, Synthesis and physical-chemical characterization of metallic nanoparticles // Dottorato di Ricerca in Scienze Chimiche Ciclo XXII. Università di Bologna. 2010.

69. C. Dwivedi, C.P. Shah, K. Singh, M. Kumar, P.N. Bajaj, An organic acid-induced synthesis and characterization of selenium nanoparticles // J. Nanotechnology, 2011, Article ID 651971, 6 pages (2011).
70. I.O. Oladeji, L. Chow, Synthesis and processing of $\mathrm{CdS} / \mathrm{ZnS}$ multilayer films for solar cell application // Thin Solid Films, 474, p. 77-83 (2005).

71. N. Revaprasadu and S.N. Mlondo, Use of metal complexes to synthesize semiconductor nanoparticles // Pure Appl. Chem., 78(9), p. 16911702 (2006).

72. K. Yamada, K. Hoshino, K. Matsumoto, I. Shimoyama, Electro-static trapping and deposition of nanoparticles in a submicron narrow gap for a lateral-electrode LED // $17^{\text {th }}$ IEEE Intern. Conf. (MEMS), Micro Electro Mechanical Systems 2004. p. 49-52 (2004).

73. D.J. Suh, O.O. Park, H.-T. Jung, M.H. Kwon, Optical properties and characteristics of the CdSe nanoparticles synthesized at room temperature // Korean J. Chem. Eng. 19(3), p. 529-533 (2002).

74. J. Smith, D. Mager, U. Loeffelmann, J.G. Korvink, Can inkjet printing produce MRI coils? // Proc. Int. Soc. Mag. Reson. Med. 16, p. 1126 (2008).

75. Y. Liu, W. Chen, A.G. Joly, Y. Wang, C. Pope, Y. Zhang, J.-O. Bovin, P. Sherwood, Comparison of water-soluble CdTe nanoparticles synthesized in air and in nitrogen // J. Phys. Chem. B, 110(34), p. 16992-17000 (2006).

76. S.S. Kher, R.L. Wells, New method for the synthesis of nanocrystalline gallium arsenide and gallium phosphide // J. Chem. Mater. 6(11), p. 2056-2062 (1994).

77. M.A. Malik, P. O’Brien, S. Norager and J. Smith, Gallium arsenide nanoparticles: Synthesis and characterisation // J. Mater. Chem., 13, p. 25912595 (2003).

78. S. Schulz, The chemistry of group 13/15 compounds (III-V compounds) with the higher homologues of group 15, Sb and $\mathrm{Bi} / /$ Coordination Chem. Rev. 215, p. 1-37 (2001).

79. H. Lee, M.G. Kim, C.H. Choi, Y.-K. Sun, C.S. Yoon, J. Cho, Surface-stabilized amorphous germanium nanoparticles for lithium-storage material // J. Phys. Chem. B, 109, p. 20719-20723 (2005).

80. Reference Book on Electrical Engineerings Materials. Eds. Yu.V. Koritskii, A.A. Pasynkov, B.M. Tareev. Vol. 2. Energoizdat, Moscow, 1987 (in Russian).

81. A. Costello, D. Doherty, J. LeBeau, R. Warren, Multilayer polymer inkjet printing. Report for a major qualifying project // Worcester Polytechnic Institute, England (2010).

82. S.K. Bleech, M. Santos 3D Polymer Printing with Desktop Inkjet Technology. A major qualifying project report // Worcester Polytechnic Institute, England (2009).

83. J. Perelaer, P. Kröber, J.T. Delaney, U.S. Schubert, Fabrication of two and three-dimensional structures by using inkjet printing // NIP25 and Digital Fabrication (2009), p. 791-794. 
84. R.Y. Utama, Inkjet printing for commercial highefficiency silicon solar cells. Dissertation Sheet of $\mathrm{PhD}$ in Photovoltaic Engineering // ARC Centre of Excellence for Advanced Photovoltaics and Photonics, University of New South Wales Sydney, Australia, March 2009.

85. E. Tekin, Thin film libraries of functional polymers and materials prepared by inkjet printing // Eindhoven, Technische Universiteit Eindhoven, 2007.

86. S. Liker, Use of stainless steel piezo inkjet printheads to enable jetting of aggressive etchants for improved solar PV cell processing // TridentITW Trident Solar Division, 8 Sept. 2009.

87. 256Jet-S Printhead // Information from Trident Industrial Ink Jet, 1114 Federal Road Industrial Park Drive, Brookfield, Connecticut, USA.

88. Yuan Zhao, Ming-Yu Sheng, Wei-Xi Zhou et al., A solar photovoltaic system with ideal efficiency close to the theoretical limit // Opt. Exp. A, 20(S1), p. A28-A38 (2012).

89. N.V. Yastrebova, High-efficiency multi-junction solar cells: Current status and future potential // Centre for Research in Photonics, University of Ottawa, Canada, April 2007.

90. J.M. Olson, D.J. Friedman, and S. Kurtz, Highefficiency III-V multijunction solar cells // Handbook of Photovoltaic Science and Engineering. Eds. A. Luque and S. Hegedus. John Wiley \& Sons, 2003.

91. H. Antoniadis, High efficiency, low cost solar cells manufactured using 'Silicon Ink' on thin crystalline silicon wafers // Innovalight DOE report (2011), $41 \mathrm{p}$.

92. T. Kaydanova, M.F.A.M. van Hest, A. Miedaner et al., Direct write contacts for solar cells // 31st IEEE Photovoltaics Specialists Conf. and Exhibition, Lake Buena Vista, Florida, January 3-7, 2005 .
93. T. Rivkin, C. Curtis, A. Miedaner, J. Perkins, J. Alleman, D. Ginley Direct write processing for photovoltaic cells // 12th Workshop on Crystalline Silicon Solar Cell Materials and Processes, August 2002, p. 223-226 (2002).

94. R. Pasquarelli, C. Curtis, M. van Hest, Inkjet printing of nickel and silver metal solar cell contacts // J. Undergraduate Res. 8, p. 91-96 (2008).

95. V.M. Andreev, V.V. Evstropov, V.C. Kalinovskii, V.M. Lantratov, V.P. Hvostikov, Current passage and potential efficiency of sun elements on the basis of p-n-transitions from GaAs and $\mathrm{GaSb} / /$ Fizika i teknika poluprovodnikov, 43(5), p. 671-678 (2009), in Russian.

96. A. Farenbruh, R. Bube, Solar Cells. Theory and Experiment. Energoizdat, Moscow, 1987 (in Russian).

97. M.A. Green, K. Emery, Y. Hishikawa, W. Warta, Solar cell efficiency tables (version 36) // Progress in Photovoltaics: Research and Applications, 18, p. 346-352 (2010).

98. M.A. Green, K. Emery, Y. Hishikawa, W. Warta, E.D. Dunlop, Solar cell efficiency tables (version 39) // Progress in Photovoltaics: Research and Applications, 20, p. 12-20 (2012).

99. R.R. King, D.C. Law, K.M. Edmondson, et al., Advances in high-efficiency III-V multijunction solar cells // Advances in OptoElectronics, 2007, 8 pages (2007).

100. B. Mitchell, G. Peharz, G. Siefer et al., Fourjunction spectral beam-splitting photovoltaic receiver with high optical efficiency // Progress in Photovoltaics: Research and Applications, 19(1), p. 61-72 (2011). 